middle of last century in Britain, to Frerichs and Traubo in Germany, and to Bowditeh and Newell Martin in America. In conclusion, a tribute was paid to Lord Nuffield who, in making his wiso and munificent benefaction for medicine, recognized the need to aid the pre-clinical, as well as the clinical, laboratories. The lectures constituto a valuable history of the subject, and have been issued in pamphlet form by the Clarendon Press, Oxford.

\section{Currents in the South Pacific}

Ax atlas has been constructed by the Marine Division of the Meteorological Office from observations made by merchant vessels and H.M. ships during the period 1910-1937 (H.M. Stationery Office. 7s. 6d.). No previous atlas of tho currents of this ocean has been published sinco 1897. The new atlas is a definite contribution to our knowledge of the surface drifts of the oceans, for this is the first time that the currents of the South Pacific have been treated statistically. Two charts aro given for each quarter of the year. One shows the mean set and drift for each of the small areas where observations are availablo; the other chart gives roses showing the percentage frequencies of current in any direction for larger areas. In addition, the percentage frequencies of currents, flowing in the same direction, of various strengths, àre indicated. In this manner all possible information as to the variation of current is graphically illustrated. The investigation into tho currents of this ocean has brought out many im. portant points which are summarized in the text, tables and graphs.

\section{Objectives of Higher Education in India}

Reference was made in Nature of May 6, p. 757. to an article in The Mahratta about a proposal for the establishment by the Bombay Government of a Deccan College Institute for higher education in mathematics, philosophy, English, philology, Indian languages, history and economics. The paragraph in question concluded : "In view of the growth of unemployment among the educated classes ... the comment suggests itself: higher education for what ?" The writer of the article has taken exception to these words as implying " $a$ desire to restrict the functions of universities to utilitarian subjects only". They were, in fact, meant to call to mind the danger of promoting educational undertalings without a cloar sense of direction and purpose. The whole sub. ject of the unemployment of university graduates is dealt with by W. II. Kotschnig in his "Unemployment in the Learned Professions" (Oxford University" Press, 1937). In his survey of tho problem in India, he points out that unemployment is worst amongst graduates in liberal arts courses and that this is traceable to a wrong emphasis in education, too much stress being laid on higher literary and theoretical studies. A proposal to establish a new collego providing liberal arts courses for graduates appears to call for an answer to the question whether these courses are likely to qualify not merely for the con. ferment of higher degrees but also for careers which are not already overcrowded.

\section{High Resistance Resistors}

THE Zenith Electric Co., Ltd., Villiers Road, London, N.W.2, has issued a catalogue describing its wire-wound vitreous embedded resistors (resistances). They consist of a ceramic tube or rod spirally wound with resistance wire and embedded in vitreous enamel. This company was the first to produce resistors of this type in Great Britain. MIodern requirements have created a need for resistors of comparatively small size characterized by their resistance remaining steady under all working conditions. The requirements of high ohmic value necessitate resistance wires of the smallest possible gauges; they are naturally delicate and fragile, and trustworthiness makes it necessary that the wires be embedded in, and protected by, a covering absolutely. impervious to the entry of moisture or to the attacks of acids, alkalis or other deleterious substances. It must be capable also of withstanding high overloads and repeated heating and cooling, without developing flaws, crazing or cracks which would permit the entry of moisture, and quickly lead to open circuit, by the corrosion of the fine-gauge wires employed. The foregoing requirements seem to be fully met in practice by the 'ceramito' embedding process, which is much superior to ordinary vitreous enamels. Being akin to porcelain, it has very high insulating properties, possesses great mechanical strength and resists chemical attack. The new 'ceramite' resistor complies with all the latest Government specifications for tropical grade resistors.

\section{Anti-Rabic Treatment in India}

Detarls aro given in the annual report, for 1936, of the director, Dr. R. O. A. Smith, recently issued, of anti-rabic treatment carried out at tho Pasteur Institute of India, Kasauli, and its attached centres. The total number of patients attending was 24,897 , of whom 18,620, made up of 17,263 Asiatics and 1,357 Europeans, received the full courso of inoculations with vaccine. Of these, 97 Asiatics died, a death. rate of 0.56 per cent, but no Europeans. The vaccine employed was a carbolized 5 per cent emulsion of brain of sheep inoculated with Paris fixed virus, a number of cases suffering from severe. bites of rabid animals receiving anti-rabic serum treatment in addition.

The annual report of the director, Lieut.-Colonel K. R. K. Iyengar, for the year ending December 31, 1937, of the Pasteur Institute of Southern India, Coonoor, has recently been issued. At tho Institute, 426 patients, and at subsidiary centres 11,307 patients, underwent the full course of treatment. The number of deaths from rabies reported among all treated cases (complete and incompleto) was twenty-one, giving a mortality rate of 0.15 per cent. Death followed dog-bite in nineteen cases, while one death was duo to fox-bite and one to jackalbite. The shortest incubation period observed during the year was sixteen days (dog-bite) and the longest was 169 days (jackal-bite). The raccine used was Semplo's 5 per cent carbolized sheep-brain suspension of Paris fixed virus, which was in its 994th passage at the close of the year. 